Proceedings

\title{
Transhumance Offers Food Pulse to Scavengers †
}

\author{
Natividad Aguilera-Alcalá 1,*, Eneko Arrondo ${ }^{2}$, Roberto Pascual-Rico ${ }^{3}$, Zebensui Morales-Reyes ${ }^{1}$, \\ José María Gil-Sánchez ${ }^{1}$, José A. Donázar ${ }^{2}$, Marcos Moleón ${ }^{4}$ and José A. Sánchez-Zapata ${ }^{1}$
}

Citation: Aguilera-Alcalá, N.; Arrondo, E.; Pascual-Rico, R.;

Morales-Reyes, Z.; Gil-Sánchez, J.M.; Donázar, J.A.; Moleón, M.;

Sánchez-Zapata, J.A. Transhumance Offers Food Pulse to Scavengers.

Proceedings 2021, 68, x.

https://doi.org/10.3390/xxxxx

Academic Editor:

Received: date

Accepted: date

Published: date

Publisher's Note: MDPI stays neutral with regard to jurisdictional claims in published maps and institutional affiliations.

Copyright: (c) 2021 by the authors. Submitted for possible open access publication under the terms and conditions of the Creative Commons Attribution (CC BY) license (http://creativecommons.org/licenses/by/4.0/).
1 Department of Applied Biology, Miguel Hernández University of Elche, 03202 Elche, Spain; e-mail1@e-mail.com (Z.M.-R.); e-mail2@e-mail.com (J.M.G.-S.); e-mail3@e-mail.com (J.A.S.-Z.)

2 Department of Conservation Biology, Doñana Biological Station-CSIC, 41092 Seville, Spain; e-mail4@e-mail.com (E.A.); e-mail5@e-mail.com (J.A.D.)

3 Instituto de Investigación en Recursos Cinegéticos (IREC-CSIC), University of Castilla-La Mancha, 13005 Ciudad Real, Spain; e-mail6@e-mail.com

4 Department of Zoology, University of Granada, 18071 Granada, Spain; e-mail7@e-mail.com

* Correspondence: naguilera@umh.es

+ Presented at the 1st International Electronic Conference on Biological Diversity, Ecology and Evolution, 1531 March 2021; Available online: https://bdee2021.sciforum.net/.

Abstract: Transhumance is an extensive livestock technique that consist on the seasonal movement of herds to take advantage of natural high-quality pastures. Extensive pastoralism modulates the landscape, provide ecosystem services as well as feeding opportunities for scavengers. However, transhumance is in decline mainly due to socio-economic changes, so the availability of food for scavengers may be changing. With the aim to evaluate the remaining effect of transhumance, we explored the changes that occur in a summer pasture ecosystem according to the presence or absence of livestock. The study was located in a high plateau of pastures in the south of the Iberian Peninsula, located in the Natural Park of Sierra de Cazorla, Segura y las Villas where about 35,000 units of livestock, mainly sheep, move there to graze in summer. We evaluated the changes in the abundance of obligate and facultative scavengers by field surveys, as well as the response of local wild ungulates in presence and absence of livestock. We also evaluated the individual foraging behavior of the main scavengers by GPS monitoring of 30 adult griffon vultures (Gyps fulvus) for four years. Surveys shown a positive populational response of griffon vultures in presence of livestock and an increase of GPS locations, especially noteworthy in non-breeding individuals. However, facultative scavengers and wild ungulates abundances remain unaltered throughout the year. The combination of census sampling and GPS monitoring allowed us to better understand the ecosystem dynamics. Traditional extensive livestock farming has a functional ecological response in scavengers, so current changes in this practice may affect them in future scenarios.

Keywords: pastureland; vultures; tracking; farming; ungulates 